\title{
Different views on ethics: how animal ethics is situated in a committee culture
}

Malin Ideland

School of Teacher Education

Malmö University

20506 Malmö

Sweden

e-mail: malin.ideland@mah.se

telephone: +46-739-55 2277

Key words: Animal ethics committees, Cost-benefit evaluation, Situated ethics, Sociology of expectations, Consensus 


\begin{abstract}
:
Research including non-human animal experimentation is fundamentally a dilemmatic enterprise. Humans use other animals in research to improve life for their own species. Ethical principles are established to deal with this dilemma. But despite this ethical apparatus, people who in one way or another work with animal experimentation have to interpret and understand the principles from their individual points of view. In interviews with members of Swedish animal ethics committees, different views on what the term "ethics" really means were articulated. For one member, the difficult ethical dilemma of animal experimentation is the lack of enriched cages for mice. For another, the ethical problem lies in regulations restraining research. A third member talks about animals' right not to be used for human interests.

These different views on "ethics" intersect once a month in the animal ethics committee meetings. There is no consensus on what constitutes the ethical problem that the members should be discussing. Therefore, personal views on what "ethics" means, and hierarchies among committee members, characterize the meetings. But committee traditions and priorities of interpretation as well are important to the decisions. In the present paper, I intend to discuss how "ethics" becomes situated and what implications this may have for committees' decisions.
\end{abstract}




\section{INTRODUCTION}

Animal ethics committees are supposed to perform critical cost-benefit evaluations for every single experiment that includes use of non-human animals. But what does this cost-benefit evaluation include? Whose costs and whose benefits are to be compared and evaluated? Many actors and many needs are included in the animal ethics reviews. Science "must" move forward. Patients "must" have better medicines and treatments. Laboratory animals "must" be treated in a responsible way. To understand how the cost-benefit evaluations are really carried out, it is important to look at how the ethical discussions are situated in: 1) the individual members' different interests and interpretations of the mission of animal ethics committees and 2) the meeting context.

Interviews with members of Swedish animal ethics committees show that there are individual interpretations of the mission of the animal ethics committees. In the present article, I will discuss what impact these different views on ethics have on the ethical reviews and how ethics becomes situated in the context of the committee meeting ${ }^{1}$. In what ways do the "outcomes" of the ethical discussions relate to the committee culture, where priorities of interpretation, relations between members, wishes for consensus and expectations built on the past, present and future have strong impact on the outcome of the ethical reviews? Benhabib's concept of situated ethics ${ }^{2}$ and theories from the sociology of expectations ${ }^{3}{ }^{4}$ will be used for the analysis.

\section{Background}

In Sweden, seven local animal ethics committees examine applications for all non-human animal experiments. Each of the seven committees consists of a chairperson, six scientific experts and six laypersons. The scientific experts come from universities and drug companies. This category also includes animal technicians and veterinarians. The laypersons represent local political parties or animal welfare organizations ${ }^{5}$. In the committees you can find future Nobel Prize candidates, people who have never seen a laboratory and animal rights activists. They are actors with dissimilar agendas and different backgrounds, and one can easily imagine how this committee composition could stimulate lively discussions and conflict situations at the meetings - and perhaps also rejection of applications. Despite this, in 2003, 1733 cases were handled, and 99 percent of all applications were approved - sometimes with requested modifications ${ }^{6}$. Only 22 cases were rejected ${ }^{7}$.

The committees' task is to make cost-benefit evaluations. Is the animals' suffering counterbalanced by the expected benefits of the research? The committees are also 
supposed to discuss every single application on the basis of The Three Rs: Refinement, Reduction and Replacement ${ }^{8} 910$.

\section{METHOD}

An ethnographic approach was used in the study to gain an understanding of how individual views on ethics are represented in the committees' decisions. Twenty members have been interviewed during 2006 and 2007. Among them, three persons represent animal welfare (AW) or animal rights movements (AR), six are politically elected community members $(\mathrm{CM})$, ten are scientific experts (SE) from different disciplines and one work as animal technician (AT). The interviews were semi-structured and participant driven. They lasted on average 1.2 hours. Questions were open-ended and allowed the members to elaborate on their thoughts. Interviews were tape-recorded and transcribed ${ }^{11}$.

The questions treated the members' handling of dilemmas associated with animal experimentation in general (particularly with transgenic animals), definitions of ethics and their understanding of The Three Rs, relations between committee members, the public debate, and relations between humans and other animals and between different species. These themes have been coded in the transcripts. The transcripts have also been sent to the interviewees for approval.

Twelve meetings in six different committees have been observed. Eight of the meetings were plenary meetings and four were held in preparatory groups. The observation protocols mostly focused on relations between members, if and how different dilemmas with a special focus on GM animals are articulated and discussed, and how different species are discussed.

\section{FINDINGS}

\section{Interpretations of the ethical evaluation}

Almost all the interviewed members express that ethics is about making cost-benefit evaluations. The animals' suffering must be seen in light of the purpose of the research. But when the committee members develop this question, different views on what this statement really means emerge. On a discursive level, they agree on what their mission is, but inside this framework, individual interpretations of what this cost-benefit evaluation refers to are set out. The definition of the ethical question the committee is supposed to discuss varies. I have found three different categories: Ethics in the name of animals; Ethics in the name of science; Ethics in the name of patients ${ }^{12}$. The different views are categorized on the basis of whose 
point of view the committee members present when they talk about ethics. Who is going to benefit from the ethical evaluation?

\section{In the name of Animals}

Most of the informants represent the view "Ethics in the name of the animal". The main concern of both scientific experts and laypersons is animal welfare. John summarizes ethics as "It is to make sure the laboratory animals have a fair existence" (John, CM). Pia (AT) means that the ethical questions that should be discussed are about the animals' well-being, like endpoints, housing and handling. Maria (SE) talks about the social environment for the animals. These people focus the animal in their ethical evaluation; they imply that this is what should be discussed at the committee meetings. Sofia (AR) also focuses on the animals.

"My basic opinion is that animals have rights, and one of these rights is to not suffer. And almost every animal experiment causes some suffering, and it is just for our-human beings' - benefit that all animal experiments are done. I/---/ So what I do in the committee is just fix the surface and improve the animals' existence" (Sofia, AR.).

Ethics in the name of the animal can be articulated in different ways. John, Maria and Pia talk about this category of ethics on a very practical level. As does Sofia, but she also wishes to raise questions to a theoretical level - do human beings have the right to use other animals for their own well-being? However, as there is no scope for animal rights arguments in the committee meetings, she focuses on animal welfare instead of animal rights. No one besides other animal rights spokespeople consider these types of arguments to be relevant. Animal welfare issues, on the other hand, are in focus most of the time. But not everyone considers animal welfare to be the main aim of the discussions. Ethics can also be discussed in the name of science.

\section{In the name of Science}

Ethics in the name of science is here expressed by two prominent researchers. To them, it is important to be part of the committee, because then they are able to empower scientific research. 
"You could be good at accentuating research matters in the committee work. So that important research does not get stuck there because there is some animal-rights person who does not like the experiments. That can easily happen" (Peter, SE).

"We have to be there (at the meetings) to make it easier for science. If we don't work actively with these questions, they never get the right input from us. Then it is only the opposition that is heard" (Anders, SE).

This view concerns opportunities for science to evolve. It becomes unethical not to use nonhuman animal experimentation in research ${ }^{13}$. Both these men define themselves as basic researchers. They do not apply their research to patients; their primary concern is the science itself. They also highlight the enemies of research - the representatives of animal rights or animal welfare movements. These persons are defined as obstacles, their aim being to stop scientific progress and destroy the hopes and expectations of many severely ill people who are dependent on animal experiments. This leads us to the next category.

\section{In the name of Patients}

Marianne has worked as a medical doctor. She talks a great deal about the different costs of not using animal experimentation - "for the individual patient, families, society. Everything" (Marianne, SE). Her main concern is the patients. This view is also represented among laypersons: "I don't care about the animals at all, I just care for humans" (Birgit, CM). Any medical aim is almost always seen as a good enough purpose. The hope for human health legitimizes the research ${ }^{14}{ }^{15}$.The hopes and expectations for medical improvement shadow all other ethical aspects, a pattern that is recognizable in several debates on new biotechnologies $^{16} 17$.

In the interviews, there are very few examples of how members question medical purposes. Marianne, for example, talks a great deal about the importance of scrutinizing the purpose of the research. But when I ask her whether there are purposes that researchers question, she hesitates:

"It can happen... I have no example, but it does not happen often. Often those projects have been stopped before the application for ethical evaluation has reached us. If a project has a strange purpose it has been stopped by supervisors and others" (Marianne SE). 
No purpose is a bad enough to be rejected. The idea that the purpose of the research should be evaluated in relation to the suffering of animals is very seldom put into practice. The scientific experts agree that research is (almost) always necessary - in the name of science or in the name of the patients. The rhetoric varies, but the content is the same. It is not unethical to use animals in research. It is unethical not to do so.

\section{Cost-benefit evaluations?}

The notion that animal ethics committees should be evaluating the relation between suffering and benefit may include many different views on what this actually means. As shown above, it may focus on the research climate as well as on discussions of what constitutes necessary research, future patient benefits, animal rights or what kind of enrichment rats need in their cages. The definition of the committees' mission varies greatly among the committee members. What are the implications of this variation? On the one hand, it is a problem, as there is no common sense of what aspects of animal experimentation they are going to evaluate. Therefore there is a risk that just one view will be expressed in the meetings. On the other hand, this variation could be a fantastic opportunity; the committee members can point out different ethical aspects at the meeting and contribute to an important discussion about costs and benefits, which is the very idea behind the committees' composition ${ }^{18}$. But how does the discussion unfold in the meetings? Are there any multi-faceted cost-benefit evaluations?

\footnotetext{
"We are only discussing questions about details. /---/ I would like to discuss more about the purpose of the experiment" (Sofia, AR).
}

"A lot of what we are discussing - someone has even claimed that 99\% of what we are discussing isn't ethics, it is something else" (Anders, SE).

Most of the interviewees agree that the animal ethic committees are discussing the "wrong" questions. They all know that they are supposed to be conducting cost-benefit evaluations, but they are instead discussing experimental methodology. They talk almost exclusively about refinement questions, and not about research purposes, replacement and reduction. Why is this the case?

\section{DISCUSSION}


To understand the focus on technical questions, it is necessary to look at how the ethical evaluation is related to the context of the committee meeting. Here, ethics is viewed as something that is negotiated contextually and situationally. Benhabib ${ }^{19}$ calls this "situated ethics". In different contexts and environments, unspoken strategies are created to make ethical dilemmas easier to handle 202122 . Knorr-Cetina ${ }^{23}$ calls this process "the power of the lab". Similar processes are probably developed at the ethics committees' negotiating table; perhaps we are dealing with the "power of the committee meeting", which results in 99 percent of applications being approved. What are the unspoken strategies that characterize these meetings? Why does the context of the committee meeting invite discussions on technical questions rather than cost-benefit evaluations? Schuppli and Fraser ${ }^{24}$ point out the predominance of scientific experts as an explanation for why Canadian committees' discussions often are centred on technical issues. In Sweden, half of the committees consist of laypersons, and the discussions still focus on methodological and technical issues. I will suggest a few other explanations for this reduced ethical review.

\section{Priority of interpretation}

One reason why mostly technical issues are on the committees' agenda may concern who and what discourse - has the priority of interpretation in this context. Even if the scientific experts are not in the majority, they have power over the agenda. Observations from the committee meetings show that the priority of interpretation belongs - exclusively - to scientific ideals. There is no room for ethical questions about research purposes and animal suffering in this context. This becomes an unspoken issue, even though members agree that this is their mission.

The discourse used in the discussions is scientific, and the ethical issues discussed are related to the experiment itself. Representatives of animal welfare and animal rights organizations have often adopted this discourse, and talk about minimizing suffering from a scientific point of view. They have often read scientific journals, are informed about new - more humane - technical solutions and talk about animal experimentation in scientific terms. Using this strategy, they are included in the discussion, and listened to. When they try to raise questions about animal rights, they are considered radical activists and therefore easily dismissed.

The community members' mission is to serve as an interface between the public and the research institutions, and raising ethical questions ${ }^{25} 26$ is difficult to carry through. Attitude surveys also show that the public is concerned about ethics, safety and value in 
relation to using non-human animals in research ${ }^{27}$. But in the committee discussions, the public representations view is limited to a patient-oriented desire for biomedical solutions. This priority of interpretation prevents a discussion including animal concerns issues and worries of the public. Instead, the scientific experts confront the lay people with "the best solution" 2829 .

\section{Consensus}

Another reason why mainly technical problems are discussed is that, on these issues, members can reach a consensus. Moreno ${ }^{30}$ shows the importance of consensus in the culture of bioethics. As we have seen, it may be difficult for members to reach a consensus if the research purpose is - or is not - good enough to justify animal suffering. The cost-benefit evaluation becomes too complex in a context where consensus is supposed to be reached and therefore it becomes a non-issue in the committee. But one theme all members can agree on is how to minimize the suffering of animals. Solutions can be found in relation to the most technical aspects, at least they can agree on a humane end-point, when the animal will be put to death. Better technical solutions benefit scientific research as well as the animals. They probably also benefit patients. Decreasing suffering can be done in the name of science, in the name of patients and in the name of animals.

In the committee meetings, there can also be a consensus surrounding hope. Those who cannot understand the magic and greatness of scientific progress are seen as fundamentalists - in this case "animal rights activists". The social construction of "The Other" in debates on biotechnologies is a strong force in strategies used to reach a consensus about the "right" decision".

\section{Expectations}

The hegemonic social discourse is that biotechnology, including for example use of transgenic animals and embryonic stem cell research, is the modern salvation - the hope for humanity. In the public discourse, biotechnologies are almost synonymous with the language and imagery of futuristic breakthroughs ${ }^{32}$. In this discourse, medical reason is always a good enough reason to use animals as well as embryos for health purposes. The hope of biotechnological salvation shadows concerns about experimental animals. The expectations of technology are performative, because they mobilize the future into the present using mutually binding promises and agendas, often articulated as "progress" or "the good life" 33 . 
At the same time, the scientific experts, who have the priority of interpretation, use historical narratives, in which animal rights activists are able to stop scientific breakthroughs. Thus, ethics is not only situated in the context of the committee meeting, but, as Brown writes, also temporally situated in "relation to memories of past futures and future presents" ${ }^{\prime 4}$. Narratives about history and the future have a strong influence on the ethics of the present. The discursive fear of historical animal rights activism, and the hopeless future that would follow in its tracks, shadows opportunities to question animal experimentation from any point of view.

\section{CONCLUSIONS}

Members of the Swedish animal ethics committees agree that they are supposed to perform cost-benefit evaluations and scrutinize research aims in relation to animal suffering. But the individual interpretations of why they are doing this, and in whose name, differ. Ethical reviews can be made in the name of science, patients and animals. This intersection of different views could be an interesting foundation for complex cost-benefit evaluations, but in the meetings, the discussions focus on technical and methodological improvements instead of on weighing research aims against animal suffering.

This reduced ethical evaluation can be understood from the perspective of situated ethics. The ethics is situated in the context of the committee meeting and the relations between committee members. The committee culture is strongly characterized by a scientific priority of interpretation and a desire for consensus. The discussions on use of animals are also situated in the future and in the past; in the hopes for scientific progress, medical solutions, but also in narratives about the historical threats posed by animal rights activists. A more open discussion climate and a focus on present research could build a better foundation for real cost-benefit evaluations, and offer better possibilities for committee members to fulfil their mission.

\section{Acknowledgements and funding}

I thank Tora Holmberg, Nik Brown, Susanne Lundin and Helena Röcklingsberg for comments on this paper. The article is an outcome of the project Dilemmas with transgenic animals, funded by the Swedish Research Council.

1 Benhabib, S. Situating the Self. Gender, Community and Postmodernism in Contemporary Ethics. Cambridge: Polity. 1992. 
${ }^{2}$ Benhabib, S. Situating the Self. Gender, Community and Postmodernism in Contemporary Ethics. Cambridge: Polity. 1992.

3 Brown, N. Hope Against Hype - Accountability in Biopasts, Presents and Futures. In: Science Studies 2/2003, Vol 16, p 3-21. 2003.

4 Borup, M. Brown, N. Konrad, K. \& van Lente, H. The Sociology of Expectations in Science and Technology. In: Technology Analysis and Strategic Management. Vol 18. Nos. 3/4, 285-298. July-September 2006.

5 For further discussion on the committees' composition, see Forsman, B. Research Ethics in practice: the animal ethics committees in Sweden 1979-1989. Göteborg: Centre for Research Ethics. 1993.

6 Hagelin, J, Hauu, J \& Carlsson, HE. The Refining Influence on Animal Experimentation in Sweden. In: Laboratory Animals, 2003, 37, p 10-18.

7 There is great variation between different committees; some do not reject a single application, while others have a rejection rate of $10 \%$ (Nordgren, A \& Röcklinsberg, H. "Genetically modified animals in research: an analysis of applications submitted to animal ethics committees in Sweden", Animal Welfare, 2004).

8 Russel, W.M.S. \& Burch, R.L. The Principles of Humane Experimental Technique. London: Methuen. 1959.

9 Schuppli, C., Fraser, D, McDonald, M. Expanding the Three Rs to Meet New Challenges in Humane Animal Experimentation. ATLA, 2004, 32, p 525-532

${ }^{10}$ In the present article, committee members' understanding of The Three Rs is not discussed. The focus is instead on how they interpret what constitutes the ethical issue they are supposed to review, how they understand the cost-benefit evaluation and what interpretations characterize the discussions in the committee meetings.

${ }^{11}$ All interviews were conducted in Swedish, and the translations of the quotes are mine.

12 These different ethical views can probably be related on a theoretical level to different philosophical theories concerning animal welfare and animal rights (cf. Forsman, B. Research Ethics in practice: the animal ethics committees in Sweden 1979-1989. Göteborg: Centre for Reseach Ethics. 1993, Gluck, DiPasquale \& Orlans (eds): Applied Ethics in Animal Research. Philosophy, Regulation and Laboratory Applications. West Lafayette: Purdue University Press. 2002, Armstrong, S. \& Botzler, R. The Animal Ethics Reader. London: Routledge. 2003). The aim of the present paper, however, is not to examine whether the committee members are utilitarists or speciesists. The purpose is to look into different private views and analyse their impact - or lack of impact on the committee meetings.

13 Both these scientists formulate a problem in the composition of the ethics committees. They see the representatives of animal welfare organizations as their opponents, and Anders would like to include representatives of patient organizations - laypersons who would appreciate research instead of trying to stop it in the name of animals.

${ }^{14}$ C.f. Orlans, BF. In the name of science. Issues in responsible animal experimentation. New York: Oxford University Press. 1993

15 Brown, N. Hope Against Hype - Accountability in Biopasts, Presents and Futures. In: Science Studies 2/2003, Vol 16, p 3-21. 2003.

16 Brown, N. Hope Against Hype - Accountability in Biopasts, Presents and Futures. In: Science Studies 2/2003, Vol 16, p 3-21. 2003.

17 Borup, M. Brown, N. Konrad, K. \& van Lente, H. The Sociology of Expectations in Science and Technology. In: Technology Analysis and Strategic Management. Vol 18. Nos. 3/4, 285-298. July-September 2006.

18 Forsman, B. Research Ethics in practice: the animal ethics committees in Sweden 1979-1989. Göteborg: Centre for Research Ethics. 1993

19 Benhabib, S. Situating the Self. Gender, Community and Postmodernism in Contemporary Ethics. Cambridge: Polity. 1992.

20 Lundin, S. Moraliska räkenskaper. In: Lundin, S (ed): En ny kropp. Essäer om medicinska visioner och personliga val. Lund: Nordic Academic Press. 2004

${ }^{21}$ Lynch, M. Sacrifice and the transformation of the animal body into a scientific object: laboratory culture and ritual practice in the neurosciences. Social Studies of Science. 18, 2:65-289. 1988.

${ }^{22}$ Holmberg, T. "A feeling for the animal": On becoming an experimentalist. Forthcoming in Society and Animals.

23 Knorr-Cetina, K. Epistemic cultures - how sciences make knowledge, Harvard University Press. 1999. 24 Schuppli, C \& Fraser, D. Factors Influencing the Effectiveness of Research Ethics Committees. Journal of Medical Ethics, 2007, 33, p 294-301.

${ }^{25}$ Orlans, BF. In the name of science. Issues in responsible animal experimentation. New York: Oxford University Press. 1993

${ }^{26}$ Sengupta, S., Lo, B. The Roles and Experiences of nonaffiliated and non-scientist members of institutional review boards. Acad Med, 2003, 78, p 212-8.

${ }^{27}$ Hagelin, J, Carlsson H-E \& Hau, J. An overview of surveys on how people view animal experimentation: some factors that may influence the outcome. Public Understanding of Science, 12:2003, p 67-81. 
${ }^{28}$ Eklöf, J. Gene Technology at Stake. Swedish Governmental Commissions on the Border of Science and Politics. Umeå: Department of Historical Studies, Umeå University, p 35.

${ }^{29}$ Hagelin, J, Carlsson H-E \& Hau, J. An overview of surveys on how people view animal experimentation: some factors that may influence the outcome. Public Understanding of Science, 12:2003, p 67-81.

30 Moreno, J. Deciding together. Bioethics and moral consensus. New York: Oxford University Press. 1995

31 In using "The Other", I am not referring to the animals, as for example Haraway does in her studies about animal experimentation (Haraway 2008), but to the opponents of animal experimentation. They are much more present in the interviews with scientists than the animals are. The ethical problem is, according to the scientific discourse, the people who have concerns about the use of animals, not the use of animals itself. The ethical evaluation should be a consensus decision made in the name of Science.

32 Brown, N. Hope Against Hype - Accountability in Biopasts, Presents and Futures. In: Science Studies 2/2003, Vol 16, p 3-21. 2003

33 Michael, M. Futures of the Present: From Performativity to Prehension. In: Brown, N. Rappert, B \& Webster, A (eds): Contested Futures: A Sociology of Prospective Techno-Science. Aldershot: Ashgate. 2000

34 Brown, N. Hope Against Hype - Accountability in Biopasts, Presents and Futures. In: Science Studies 2/2003, Vol 16, p 3-21. 2003. p 10 